\title{
ANALISIS EFEKTIVITAS BIAYA PENGGUNAAN ANTIBIOTIK PADA PASIEN SEPSIS DI RUMAH SAKIT SILOAM MANADO
}

\author{
Regita Langi ${ }^{1)}$, Widya Astuty Lolo ${ }^{1)}$, Imam Jayanto ${ }^{1)}$ \\ ${ }^{1)}$ Program Studi Farmasi FMIPA UNSRAT Manado, 95115
}

\begin{abstract}
Sepsis is a systemic disease that is often life-threatening in hospitals. Treatment with antibiotics is one of the important factors supporting the success of sepsis treatment. Because of the variety of antibiotic therapy given to sepsis patients, it is necessary to do a cost-effectiveness analysis to find out which treatment therapies are more cost-effective. This study aims to find out more cost-effective therapies between the treatment of cefotaxime and ceftazidim antibiotics in sepsis patients at Siloam Hospital Manado using descriptive research methods by retrospective retrieval of data from January to December 2018. The sample in this study were 19 patients consisting of 12 patients who used cefotaxime antibiotics and 7 patients who used ceftazidim antibiotics. The results showed that cefotaxime antibiotic therapy was more cost-effective with an ACER value of IDR. 873,114/day and ICER value of IDR. 176,390/day.
\end{abstract}

Keyword: Cost Effectiveness Analysis, Pharmaconomics, Antibiotics, Sepsis.

\begin{abstract}
ABSTRAK
Sepsis merupakan penyakit sistemik yang sering mengancam jiwa di rumah sakit. Terapi dengan menggunakan antibiotik adalah faktor keberhasilan dalam pengobatan sepsis. Karena beragamnya terapi antibiotik yang diberikan kepada pasien sepsis perlu dilakukan analisis efektivitas biaya untuk dapat mengetahui terapi pengobatan mana yang lebihcost-effective. Penelitian ini bertujuan untuk mengetahui terapi yang lebih cost-effective antara pengobatan antibiotik sefotaksim dan seftazidim pada pasien sepsis di RS. Siloam Manado dengan menggunakan metode penelitian deskriptif dengan pengambilan data secara retrospektif pada periode Januari - Desember 2018. Sampel dalam penelitian ini sebanyak 19 pasien yang terdiri dari 12 pasien yang menggunakan antibiotik sefotaksim dan 7 pasien yang menggunakan antibiotik seftazidim. Hasil penelitian menunjukan terapi antibiotik sefotaksim lebih cost-effective dengan nilai ACER sebesar Rp. 873.114/hari dan nilai ICER sebesar Rp. 176.390/hari.
\end{abstract}

Kata Kunci : Analisis Efektivitas Biaya, Farmakoekonomi, Antibiotik, Sepsis. 


\section{PENDAHULUAN}

Sepsis adalah kondisi medis yang ditandai dengan adanya peradangan diseluruh tubuh sebagai respon berlebih terhadap infeksi (Dellinger, 2012). Sebanyak 13 juta orang di dunia mengalami sepsis tiap tahun serta empat juta orang meninggal karenanya (Levy, 2010). Sepsis mewakili subgrup Systemic Inflamatory Response Syndrom (SIRS) dalam terminologi kesehatan (Suharjo, 2007). Sumber infeksi sepsis terbesar berasal dari saluran pernapasan dengan penyebab umum berupa pneumonia nosokomial dan pneumonia komunitas yang biasanya disebabkan oleh pseudomonas aeruginosa, atau Staphylococcus Aureus (Sodik, 2012).

Manajemen pasien sepsis memerlukan pendekatan terpadu tindakan diagnostik dan inisiasi cepat terapi antibiotik. Terapi antibiotik merupakan salah satu penunjang keberhasilan dalam pengobatan sepsis dan harus segera dimulai dalam 1-2 jam pertama saat didiagnosis sepsis. Karena keterlambatan pemberian terapi antibiotik dalam kurun waktu 24 jam setelah pasien didiagnosis sepsis akan menyebabkan pasien meninggal (Levy, 2010).

Alternatif terapi antibiotik bagi pasien sepsis perlu disesuaikan dari aspek terapi dan aspek biaya. Analisis efektifitas biaya (Cost Effectiveness Analysis/ CEA) untuk menilai perbandingan manfaat kesehatan dan sumber daya dalam program pelayanan kesehatan. CEA adalah suatu metode farmakoekonomi untuk memilih dan menilai program atau obat yang terbaik pada beberapa pilihan terapi dengan tujuan yang sama (Rahayu, 2013). Sehingga $C E A$ bukan dilihat dari biaya yang paling murah tetapi optimalisasi biaya (Murti, 2013). Antibiotik sefotaksim dan seftazidim dibandingkan dengan antibiotik meropenem mendapatkan hasil bahwa meropenem lebih cost-effective dibandingan antibiotik sefotaksim dan seftazidim (Putri, 2017).

Berdasarkan latar belakang di atas, peneliti melakukan penelitian tentang analisis efektivitas biaya penggunaan antibiotik sefotaksim dan seftazidim pada pasien sepsis di rumah Sakit Siloam Manado.

\section{METODOLOGI PENELITIAN Tempat dan Waktu Penelitian}

Penelitian ini dilakukan pada bulan April 2019 - Oktober 2019 di Rumah Sakit Siloam Manado.

\section{Jenis dan Rancangan Penelitian}

Jenis dan rancangan penelitian yang digunakan ialah penelitian deskriptif dengan pengambilan data secara retrospektif.

\section{Populasi dan Sampel Penelitian}

\section{Populasi}

Populasi penelitian ini adalah semua pasien rawat inap pdengan diagnosa sepsis ringan di RS Siloam Manado yang di ambil dari data rekam medik.

\section{Sampel}

Sampel pada penelitian ini yaitu pasien rawat inap dengan diagnosa sepsis ringan di RS Siloam manado harus memenuhi kriteria sebagai berikut :

A. Kriteria Inklusi

1) Pasien rawat inap yang didiagnosa sepsis ringan dengan sumber infeksi pernapasan bawah $\geq 18$ tahun.

2) Pasien sepsis yang diberi terapi antibiotik sefotaksim atau seftazidim.

3) Pasien sepsis dengan catatan rekam medik yang lengkap.

B. Kriteria Eksklusi :

1) Pasien sepsis sumber infeksi pernapasan dengan penyakit penyerta.

2) Pasien sepsis sumber infeksi pernapasan yang men erima antibiotik kombinasi. 
3) Pasien sepsis sumber infeksi pernapasan dengan catatan rekam medik yang cacat.

\section{Pengambilan Data}

Data yang digunakan dalam penelitian ini diambil dari catatan rekam medik pasien serta perincian biaya medik langsung dibagian administrasi dan keuangan di Rumah Sakit Siloam Manado periode Januari - Desember 2018.

\section{Analisis Data}

Data dianalisis secara deskriptif dan diuraikan dalam bentuk tabel. Data yang dicatat meliputi identitas, perincian biaya pengobatan sepsis dan perawatan serta biaya rawat inap. Setelah data terkumpul, dilakukan perhitungan biaya medik langsung. Pada setiap pasien. Kemudian dijumlahkan masingmasing sesuai penggunaan obat lalu dibuat rata-ratanya. Data biaya medik tersebut dapat digunakan untuk menghitung Avarage CostEffectiveness Ratio (ACER) sebagaimana pada rumus di bawah ini :

$$
A C E R=\frac{\text { BIAYA }}{\text { EFEK }}
$$

Keterangan :

Biaya $=$ Rata-rata biaya pengobatan.

Efek = outcome (efek) terapi obat.

Hasil dari CEA dapat disimpulkan dengan ICER (Incremental Cost-Effectiveness Ratio) seperti rumus berikutini :

Keterangan :

$$
I C E R=\frac{\Delta \text { Biaya }}{\Delta \text { Efek }}=\frac{\text { Biaya A-Biaya B }}{\text { Efek A-Efek B }}
$$

Biaya $\mathrm{A}=$ Biaya Teknologi Baru

Biaya $\mathrm{B}=$ Biaya Pembanding

Efek $\mathrm{A}=$ Efek Teknologi Baru

Efek $\mathrm{B}=$ Efek Pembanding.

\section{HASIL DAN PEMBAHASAN \\ 1. Angka Kejadian Sepsis}

Angka kejadian penyakit sepsis rawat inap di Rumah Sakit Siloam Manado pada periode Januari - Desember tahun 2018 yaitu berjumlah 123 pasien. Pada pengolahan data selanjutnya diambil 19 data pasien yang menerima terapi antibiotik Sefotaksim dan Seftazidim yang dinyatakan sembuh dengan status pasien umum. Berdasarkan sampel tersebut, diperoleh hasil data karakteristik pasien sepsis yang menerima obat Sefotaksim dan Seftazidim sebagai berikut.

\section{Tabel 1. Karakteristik Usia Pasien Sepsis Rawat Inap di RS Siloam Manado.}

\begin{tabular}{ccc}
\hline Umur & $\begin{array}{c}\text { Jumlah } \\
\text { Pasien (n) }\end{array}$ & Presentase \\
\hline $36-45$ & 5 & $26 \%$ \\
\hline $46-55$ & 10 & $53 \%$ \\
\hline $56-65$ & 4 & $21 \%$ \\
\hline Total & $\mathbf{1 9}$ & $\mathbf{1 0 0 \%}$ \\
\hline
\end{tabular}

Berdasarkan pada Tabel 1, data yang didapat pasien dengan kelompok usia 46-55 tahun lebih beresiko mengalami penyakit sepsis. Usia 46-55 tahun termasuk dalam golongan usia lansia awal (Depkes, 2009). Pada usia tersebut terjadi penurunan daya imun sehingga meningkatkan terjadinya infeksi (Kasmed, 2007). Tingkat kejadian sepsis paling banyak terjadi pada usia lansia awal 46-55 tahun dan lansia akhir usia 56-65 tahun (Nurul, 2015). Semakin meningkatnya usia akan dikaitkan dengan perubahan fungsi imun tubuh yaitu berkurangnya kemampuan leukosit dalam melawan mikroba di dalam tubuh (Victoria, 2016).

Tabel 2. Karakteristik Pasien Sepsis Berdasarkan Jenis Kelamin

\begin{tabular}{ccc}
\hline Jenis Kelamin & $\begin{array}{c}\text { Jumlah } \\
\text { Pasein }\end{array}$ & $\begin{array}{c}\text { Presentase } \\
(\boldsymbol{\%})\end{array}$ \\
\hline Laki-laki & 11 & $58 \%$ \\
\hline Perempuan & 8 & $42 \%$ \\
\hline Total & $\mathbf{1 9}$ & $\mathbf{1 0 0 \%}$ \\
\hline
\end{tabular}


Berdasarkan Pada Tabel 2 menunjukan pasien sepsis dengan jenis kelamin laki-laki sebanyak 11 pasien $(58 \%)$ dan pada perempuan sebanyak 8 pasien (42\%). Beberapa penelitian dilakukan terkait hubungan jenis kelamin dengan penyakit sepsis didapatkan bahwa laki-laki lebih rentan terkena sepsis. Laki-laki cenderung mengalami infeksi di paru karena gaya hidup laki-laki pada umumnya sering merokok, sedangkan untuk perempuan lebih cenderung mengalami infeksi saluran kencing daripada paru. Penyebab tersering untuk sepsis sendiri ialah infeksi paru (Yessica, 2014). Penelitian yang melaporkan bahwa jenis kelamin tidak berpengaruh bermakna terhadap sepsis (Rheza, 2016). Sepsis tidak dipengaruhi oleh jenis kelamin tetapi dipengaruhi oleh usia dan jenis penyakit yang mendasarinya (Restiana, 2018).

\section{Analisis Efektivtas Biaya}

\section{Perhitungan Biaya Medik Langsung menggunakan Sefotaksim}

Tabel 3. Direct medical cost penggunaan terapi antibiotik sefotaksim pada pasien sepsis di RS Siloam Manado.

\begin{tabular}{|c|c|c|c|c|c|c|}
\hline \multirow[b]{2}{*}{ No } & \multirow[b]{2}{*}{ Nama } & \multirow{2}{*}{$\begin{array}{c}\text { Lama } \\
\text { Rawat } \\
\text { Inap } \\
\text { (hari) }\end{array}$} & \multicolumn{4}{|c|}{ Komponen Biaya (Rp) } \\
\hline & & & $\begin{array}{c}\text { Biaya } \\
\text { Pengobatan } \\
\text { (Rp) }\end{array}$ & $\begin{array}{c}\text { Biaya } \\
\text { Perawatan } \\
(\text { Rp) }\end{array}$ & $\begin{array}{c}\text { Biaya } \\
\text { Laboratorium } \\
(\mathbf{R p})\end{array}$ & Total Biaya (Rp) \\
\hline 1. & EM & 5 & 208.800 & 3.480 .000 & 777.000 & 4.465 .800 \\
\hline 2. & $\mathrm{AK}$ & 5 & 208.800 & 3.480 .000 & 777.000 & 4.465 .800 \\
\hline 3. & $\mathrm{AM}$ & 5 & 208.800 & 3.480 .000 & 777.000 & 4.465 .800 \\
\hline 4. & TS & 6 & 261.000 & 3.900 .000 & 777.000 & 4.938 .800 \\
\hline 5. & EB & 5 & 208.800 & 3.480 .000 & 777.000 & 4.465 .800 \\
\hline 6. & OR & 6 & 261.000 & 3.900 .000 & 777.000 & 4.938 .800 \\
\hline 7. & KT & 6 & 261.000 & 3.900 .000 & 777.000 & 4.938 .800 \\
\hline 8. & TD & 5 & 208.800 & 3.480 .000 & 777.000 & 4.465 .800 \\
\hline 9. & RW & 5 & 208.800 & 3.480 .000 & 777.000 & 4.465 .800 \\
\hline 10. & SP & 6 & 261.000 & 3.900 .000 & 777.000 & 4.938 .800 \\
\hline 11. & AP & 5 & 208.800 & 3.480 .000 & 777.000 & 4.465 .800 \\
\hline 12. & JR & 5 & 208.800 & 3.480 .000 & 777.000 & 4.465 .800 \\
\hline \multirow{2}{*}{\multicolumn{2}{|c|}{ Rerata }} & \multirow{2}{*}{5,25} & \multicolumn{3}{|c|}{ Total direct medical cost } & Rp. 55.006.200 \\
\hline & & & \multicolumn{3}{|c|}{ Direct Medical cost per pasien } & Rp.4.583.850 \\
\hline
\end{tabular}

Pada perhitungan biaya medik langsung terdapat tiga komponen biaya yaitu biaya pengobatan, biaya perawatan dan biaya laboratorium. Biaya pengobatan terdiri dari biaya antibiotik yang diresepkan dokter selama pasien dirawat inap. Pada penelitian ini hanya dihitung biaya antibiotik sebagai biaya pengobatan terapi utama pasien sepsis, sedangkan biaya perawatan terdiri dari biaya ruangan Rp.250.000/hari. Ruangan yang digunakan pasien sepsis sesuai data yang didapat yaitu ruangan kelas III. Berdasarkan tabel 3, dapat dilihat total biaya medik langsung dengan biaya terkecil yaitu Rp. 4.465.800 dan total biaya medik langsung terbesar yaitu Rp. 4.938.800. Perbedaan biaya dikarenakan adanya perbedaan lama hari rawat inap di rumah sakit karena semakin lama pasien dirawat maka semakin besar pula biaya yang akan dikeluarkan. Total direct medical cost penggunaan terapi antibiotik sefotaksim ke-12 pasien yaitu sebesar Rp. 55.006.200 dengan direct medical cost yaitu Rp.4.583.850/pasien. Berikut ini 
perhitungan biaya medik langsung pada pasien sepsis rawat inap di RS Siloam Manado periode Januari - Desember 2018 yang menggunakan antibiotik Seftazidim dapat dilihat pada tabel 4 .

\section{Perhitungan Biaya Medik Langsung menggunakan Seftazidim}

Tabel 4. Direct medical cost penggunaan seftazidim pada pasien Sepsis di RS Siloam Manado.

\begin{tabular}{|c|c|c|c|c|c|c|}
\hline \multirow[b]{2}{*}{ No } & \multirow[b]{2}{*}{ Nama } & \multirow{2}{*}{$\begin{array}{c}\text { Lama } \\
\text { Rawat } \\
\text { Inap } \\
\text { (hari) }\end{array}$} & \multicolumn{4}{|c|}{ Komponen Biaya (Rp) } \\
\hline & & & $\begin{array}{c}\text { Biaya } \\
\text { Pengobatan } \\
\text { (Rp) }\end{array}$ & $\begin{array}{c}\text { Biaya } \\
\text { Perawatan } \\
(\mathbf{R p})\end{array}$ & $\begin{array}{c}\text { Biaya } \\
\text { Laboratorium } \\
(\mathbf{R p})\end{array}$ & $\begin{array}{l}\text { Total Biaya } \\
\text { (Rp) }\end{array}$ \\
\hline 1 & SP & 7 & 355.200 & 4.150 .000 & 777.000 & 5.282 .200 \\
\hline 2 & GW & 6 & 296.000 & 3.900 .000 & 777.000 & 4.196 .000 \\
\hline 3 & $\mathrm{JL}$ & 7 & 355.200 & 4.150 .000 & 777.000 & 5.282 .200 \\
\hline 4 & $\mathrm{KP}$ & 7 & 355.200 & 4.150 .000 & 777.000 & 5.282 .200 \\
\hline 5 & LB & 6 & 296.000 & 3.900 .000 & 777.000 & 4.196 .000 \\
\hline 6 & MJ & 6 & 296.000 & 3.900 .000 & 777.000 & 4.196 .000 \\
\hline 7 & KB & 7 & 355.200 & 4.150 .000 & 777.000 & 5.282 .200 \\
\hline \multirow{2}{*}{\multicolumn{2}{|c|}{ Rerata }} & \multirow{2}{*}{$\mathbf{6 , 5 7}$} & \multicolumn{3}{|c|}{ Total direct medical cost } & Rp. 33.716.800 \\
\hline & & & \multicolumn{3}{|c|}{ Direct medical cost per pasien } & Rp. 4.816.685 \\
\hline
\end{tabular}

Tabel 4. memperlihatkan total biaya medik langsung penggunaan antibiotik seftazidim dengan total biaya medik langsung terkecil yaitu Rp. 4.196.000 dan terbesar yaitu Rp. 5.282.200. Perbedaan biaya dikarenakan karena perbedaan lamanya pasien di rawat di rumah sakit dan adanya perbedaan dengan harga obat antibiotik yang digunakan pasien. Total direct medical cost penggunaan antibiotik seftazidim ke-7 pasien yaitu sebesar Rp. 33.716 .800 dengan dirct medical cost yaitu Rp. 4.816.685/pasien.

\section{Perhitungan Efektivitas Biaya Berdasarkan ACER}

Tabel 5. Perhitungan ACER penggunaan Sefotaksim dan Seftazidim pada pasien sepsis Di RS Siloam Manado.

\begin{tabular}{cccc}
\hline Antibiotik & $\begin{array}{c}\text { Rata-rata direct } \\
\text { medical cost }(\mathbf{C}) \\
(\mathbf{R p})\end{array}$ & $\begin{array}{c}\text { Rata-rata lama hari } \\
\text { rawat inap } \\
\text { (Efektivitas/E) (Hari) }\end{array}$ & $\begin{array}{c}\text { ACER } \\
\text { (C/E) }\end{array}$ \\
\hline Sefotaksim & 4.583 .850 & 5.25 & 873.114 \\
\hline Seftazidim & 4.816 .685 & 6.57 & 733.133 \\
\hline
\end{tabular}

Berdasarkan tabel 5, hasil perhitungan direct medical cost per pasien yang dibagi dengan rata-rata lama hari rawat inap memperlihatkan nilai ACER pada penggunaan obat Sefotaksim Rp. 873.114. Meskipun nilai ACER sefotaksim lebih besar efektivitasnya lebih tinggi dibandingkan seftazidim. Perhitungan CEA bukan tentang biaya yang lebih murah tetapi tentang optimalisasi biaya dengan efektivitas sebuah terapi (Murti, 2013).

Angka dalam ACER menunjukan peningkatan efektivitas dengan biaya sebesar yang dibutuhkan (Lorensia,2016). Sefotaksim lebih cost-efective dibandingkan Seftazidim 
PHARMACON- PROGRAM STUDI FARMASI, FMIPA, UNIVERSITAS SAM RATULANGI,

Volume 8 Nomor 4 November 2019

untuk pasien sepsis di rumah sakit Siloam

Manado meskipun nilai $A C E R$ lebih besar.

Tabel 6. Hasil Perhitungan ICER antibiotik Sefotaksim dan Seftazidim untuk pasien sepsis RS Siloam Manado.

\begin{tabular}{ccc}
\hline $\boldsymbol{\Delta C}$ & $\boldsymbol{\Delta E}$ & ICER $(\boldsymbol{\Delta C} / \mathbf{\Delta E})$ \\
\hline $4.583 .850-4.816 .685=$ & $5.25-6.57=$ & \\
\cline { 1 - 2 }-232.835 & -1.32 & 176.390 \\
\hline
\end{tabular}

Berdasarkan Tabel 6, didapatkan hasil nilai ICER yaitu Rp. 176.390. Nilai ICER yang diperoleh merupakan besarnya biaya tambahan yang harus dikeluarkan untuk memperoleh 1 hari pengurangan lama rawat inap pada pasien sepsis jika akan dilakukan perpindahan dari Seftazidim ke Sefotaksim. Namun dalam pengambilan keputusan pemilihan pengunaan antibiotik pada pasien sepsis semua tergantung kebijakan dari dokter dan kebijakan dari rumah sakit yang disesuaikan denggan anggaran rumah sakit tersebut (Putri, 2017).

\section{KESIMPULAN}

Berdasarkan penelitian yang telah dilakukan dapat disimpulkan bahwa terapi antibiotik yang lebih cost-effective antara terapi antibiotik sefotaksim dan seftazidim pada pasien sepsis di RS Siloam Manado yaitu terapi antibiotik sefotaksim. Dengan hasil perhitungan ACER sebesar Rp. 873.114/hari dan nilai ICER sebesar $\mathrm{Rp}$. 176.390/hari.

\section{SARAN}

Perlu dilakukan penelitian farmakoekonomi pada pasien sepsis dengan diagnosa sepsis berat atau syok sepsis sehingga dapat memberikan informasi kepada pengambil kesimpulan alternatif antibiotik mana yang lebih cost-effective bukan hanya pada penderita sepsis tetapi juga penderita sepsis berat dan syok sepsis.

\section{DAFTAR PUSTAKA}

Andayani, T. M. 2013. Farmakoekonomi Prinsip dan Metodologi. Bursa Ilmu, Yogyakarta.

Dellinger, R. P., Levy, M. M., Rhodes, A., Annane, D., Gerlach, H., Opal, S. M., et al. 2009. Surviving Sepsis Campaign: International Guidelines For Management Of Severe Sepsis And Septic Shock: Critical care medicine. 41:(2), 580-637.

Departemen Kesehatan RI. 2009. Sistem Kesehatan Nasional. Jakarta: Depkes RI.

Levy, M. M. 2010. Laporan kasus sepsis. Jornal of Anestesia and Critical Care. 28:(3), 50-58.

Lorensia, A., Doddy, D.Q. 2016. Farmakoekonomi Edisi Kedua. UBAYA, Surabaya.

Murti, T. M. 2013. Farmakoekonomi, Prinsip dan Metodologi. Yogyakarta. Penerbit : Bursa Ilmu.

Putri, K. N. 2017. Analisis Efektivitas Biaya Penggunaan Antibiotik Terhadap Pasien Sepsis Di RSD dr. Soebandi Tahun 2014-2015. e-Jurnal Pustaka Kesehatan. 5:(1), 155-156. 
Rahayu, Sinuraya. 2013. Analisis Efektivitas biaya Penggunaan Antibiotik Pasien Sepsis Di Rumah Sakit Bandung. Jurnal Farmasi Klinik Indonesia. 2:(2), 77-84.

Rheza, N.T., Diana, C.L., Lucky, K. 2016, Profil Penderita Sepsis di RSUP. Dr.

R. D. Kandou Manado, Journal of eClinic. 4:(1), 55-63.

Sodik, D. C., Pradipta, IS., Lestari, K. 2012. Pola Penggunaan Antibiotik dan Pola Kuman pada Pasien Sepsis Rawat Inap RSUP Dr. Hasan Sadikin Bandung, [Skripsi]. Fakultas Kedokteran, Universitas Padjadjaran, Bandung.

Suharjo J. B., Cayono, B. 2007. Terapi Antibiotika Empiris Pada Sepsis Berdasarkan Organ Terinfeksi. Dexa Medica 20:(2), 85-90.

Vicoria, N., 2014. Karakteristik Dasar Pasien Sepsis Yang Meninggal Di ICU RSUP Dr. Kariadi Semarang Periode 1 Januari-30 Desember 2014, [Skripsi]. Fakultas Kedokteran, Universitas Diponegoro, Semarang.

Yessica, P.H., 2014. Faktor Resiko Sepsis Pada Pasien Dewasa Di RSUP. Dr. Kariadi Semarang, [Skripsi]. Fakultas Kedokteran, Universitas Diponegoro, Semarang. 